\title{
Prognostic Relevance of Elevated Plasma Osmolality on Admission in Acute Decompensated Heart Failure With Preserved Ejection Fraction: Insights From PURSUIT-HFpEF Registry
}

Akito Nakagawa ( $\nabla$ a-nakagawa@cardiology.med.osaka-u.ac.jp )

Amagasaki Chuo Hospital

Yoshio Yasumura

Amagasaki Chuo Hospital

Chikako Yoshida

Amagasaki Chuo Hospital

Takahiro Okumura

Amagasaki Chuo Hospital

Jun Tateishi

Amagasaki Chuo Hospital

Junichi Yoshida

Amagasaki Chuo Hospital

Shunsuke Tamaki

Osaka General Medical Center

Masamichi Yano

Osaka Rosai Hospital

Takaharu Hayashi

Osaka Police Hospital

Yusuke Nakagawa

Kawanishi City Hospital

Takahisa Yamada

Osaka General Medical Center

Daisaku Nakatani

Osaka University Graduate School of Medicine

Shungo Hikoso

Osaka University Graduate School of Medicine

Yasushi Sakata

Osaka University Graduate School of Medicine 


\section{Research Article}

Keywords: HFpEF, plasma osmolality, prognosis

Posted Date: December 28th, 2020

DOl: https://doi.org/10.21203/rs.3.rs-131158/v1

License: (c) (i) This work is licensed under a Creative Commons Attribution 4.0 International License. Read Full License 


\section{Abstract}

\section{Background}

Complicated pathophysiology makes it difficult to identify the prognosis of heart failure with preserved ejection fraction (HFpEF). While plasma osmolality has been reported to have prognostic importance, mainly in heart failure with reduced ejection fraction (HFrEF), its prognostic meaning for HFpEF has not been elucidated.

\section{Methods}

We prospectively studied 960 patients in PURSUIT-HFpEF, a multicenter observational study of acute decompensated HFpEF inpatients. We divided patients into three groups according to the quantile values of plasma osmolality on admission. During a follow-up averaging 366 days, we examined the primary composite endpoint of cardiac mortality or heart failure re-admission using Kaplan-Meier curve analysis and Cox proportional hazard testing.

\section{Results}

$216(22.5 \%)$ patients reached the primary endpoint. Kaplan-Meier curve analysis revealed that the highest quantile of plasma osmolality on admission (higher than $300.3 \mathrm{mOsm} / \mathrm{kg}$ ) was significantly associated with adverse outcomes (Log-rank $\mathrm{P}=0.0095)$. Univariable analysis in the Cox proportional hazard model also revealed significantly higher rates of adverse outcomes in the higher plasma osmolality on admission (hazard ratio [HR] 7.29; 95\% confidence interval [Cl] 2.25-23.92, P = 0.0009). Multivariable analysis in the Cox proportional hazard model also showed that higher plasma osmolality on admission was significantly associated with adverse outcomes (HR 4.70; 95\% Cl 1.33-17.35, $\mathrm{P}=0.0160$ ) independently from other confounding factors such as age, gender, comorbid of atrial fibrillation, hypertension history, diabetes, malnutrition, and $\mathrm{N}$-terminal pro-B-type natriuretic peptide elevation.

\section{Conclusions}

Higher plasma osmolality on admission was prognostically important for acute decompensated HFpEF inpatients.

\section{Introduction}

There are many common problems in heart failure (HF) that are linked to hospitalization and mortality.(1) Heart failure with preserved ejection fraction (HFpEF) accounts for approximately half of all HF cases, and this rate is increasing.(2) Because of their pathophysiological complexity(3), the precise mechanisms involved in HFpEF with a poor prognosis are not fully understood.

Plasma osmolality is easily estimated with a blood sample as(4): 
$2 \times[$ Serum Sodium] $+[$ blood urea nitrogen] $/ 2.8+[$ glucose $] / 18(1)$

Although the components of the formula, namely sodium(5), blood urea nitrogen(6), serum glucose(7), and other parameters interacting with osmolality such as serum albumin(8) and renal function(9) have been proven to affect the prognosis of heart failure, little has been elucidated about the prognostic meaning of osmolality itself in acute decompensated HF (ADHF).

Plasma osmolality has been reported to be influenced by well-known prognostic factors such as arginine vasopressin (AVP), the renin-angiotensin-aldosterone system (RAAS), and natriuretic peptides(10) (11) (12), which suggests that osmolality itself could be also associated with the prognosis of HF. On one hand, Vaduganathan et al. reported that lower osmolality was associated with poor outcomes in heart failure with reduced ejection fraction (HFrEF) from a post hoc analysis of the EVEREST trial.(13) Kaya et

al. also reported that low osmolality on admission correlated with a poor prognosis in HFrEF patients.(14) On the other hand, independent from left ventricular ejection fraction (LVEF), Arévalo-Lorido et al. reported higher osmolality in ADHF patients could predict worse outcomes accompanied by higher comorbidities through the National Registry of Heart Failure (RICA).(15)

Based on these previous reports, the aim of this study was to investigate further the prognostic meaning of plasma osmolality, particularly in acute decompensated HFpEF patients.

\section{Methods}

\section{The PURSUIT-HFpEF registry}

This prospective, multicenter, observational cohort study was performed in 1008 consecutive hospitalized HFpEF patients. Details of the PURSUIT-HFpEF (The Prospective mUlticenteR obServational stUdy of patlenTs with Heart Failure with preserved Ejection Fraction) registry have been described previously.(16) Briefly, in collaboration with 31 hospitals in Japan, this large-scale registry aimed to collect and record a comprehensive range of clinical data to define the pathophysiology and prognostic factors of HFpEF patients. Inclusion criteria were acute decompensated HFpEF diagnosed by the Framingham criteria for HF and the following: 1) LVEF $\geq 50 \%$ and 2) N-terminal pro-B-type natriuretic peptide (NT-proBNP) $\geq 400$ $\mathrm{ng} / \mathrm{L}$ or brain natriuretic peptide (BNP) $\geq 100 \mathrm{ng} / \mathrm{L}$ on admission. Major exclusion criteria were age $<20$ years, severe valvular diseases, acute coronary syndrome on admission, life expectancy of $<6$ months due to prognosis of non-cardiac diseases, and previous heart transplantation. The anonymized data were transferred to the data center of Osaka University Hospital for analysis via data capturing system connected with electronic medical records.(17) Written informed consent was received from each participating patient. This study, including the procedure for enrollment, conformed to the principles of the Declaration of Helsinki and was approved by the institutional review board of each participating facility, including the official institutional review board committee of Osaka University Hospital (approved on February 24, 2016). It was registered under the Japanese UMIN Clinical Trials Registration (UMIN000021831). 


\section{Study population}

A total of 1024 inpatients with HFpEF were registered from June 2016 to February 2020. Of all the participants, $16(1.6 \%)$ patients died in hospital. We should unfortunately exclude additional 48 patients due to missing of plasma osmolality on admission (missing of serum sodium; 1 , blood urea nitrogen; 2 , and glucose; 46). We finally analyzed remaining 960 (93.8\%) patients discharged alive whose plasma osmolality was calculated on admission.

\section{Plasma osmolality, nutrition status, plasma volume estimation and echocardiographic measurements}

Plasma osmolality was estimated(4) with a blood sample (Equation 1). Nutrition status was estimated with the Geriatric Nutritional Risk Index (GNRI), which was calculated using serum albumin and body mass index as described previously.(18) Systemic plasma volume was estimated with plasma volume status (PVS) using hematocrit and body weight as described previously.(19) Comprehensive echocardiographic examinations were performed by trained cardiac sonographers according to the American Society of Echocardiography guidelines.(20) LVEF was calculated with the biplane Simpson's method using apical two- and four-chamber views.

\section{Follow-up and endpoints}

The primary endpoint of the present study was cardiac mortality or re-admission for HF during the followup period. The secondary endpoints were defined as respective events of cardiac mortality and HF readmission. The duration of the follow-up period was calculated from the day of discharge until an endpoint, or at the time of the last patient contact (including teleconferencing).

\section{Statistical analysis}

Data are presented as median and interquartile range of $25 \%-75 \%$ for continuous variables and frequency/percentage for categorical variables. Continuous variables were compared using KruskalWallis test (and Steel-Dwass test for between each groups) and categorical variables were compared using Fisher's exact test (with Bonferroni adjustment for between each groups). The distributions of plasma osmolality on admission and at discharge were compared with F-test. The clinical endpoint was assessed with the Kaplan-Meier curve analysis and compared with the log-rank test. Univariable Cox proportional hazards regression models were used to calculate hazard ratios (HR) and 95\% confidence intervals (Cls) for each endpoint. Multivariable Cox regression tests for plasma osmolality of our interest were performed using covariates of clinical importance as follows: age, gender, hypertension history, diabetes mellitus, GNRI, and log-transformed NT-proBNP. All statistical tests were 2-sided and $P<0.05$ was regarded as statistically significant. Statistical analyses were performed using JMP® Pro 13.2.1, (SAS Institute Inc., Chicago IL, USA) or EZR version 1.51 (Saitama Medical Center, Jichi Medical University, Saitama, Japan).

\section{Results}




\section{Characteristics of the study population}

Distributions of plasma osmolality on admission and at discharge are shown in Figure 1. Compared with the distribution at discharge, that on admission was significantly wide and shifted to higher levels $(P<$ 0.0001 , F-test). While the normal osmolality range is known to be $275-295 \mathrm{mOsm} / \mathrm{kg},(21)$ the median on admission was $297 \mathrm{mOsm} / \mathrm{kg}$.

Demographic and clinical characteristics of the 960 patients are summarized in the left column of Tables 1 and 2. The study population had a median age of 83 years; $55 \%$ were female. Hypertension (85\%) was the most prevalent comorbidity followed by atrial fibrillation, dyslipidemia, and chronic kidney disease $(46 \%, 41 \%$, and $40 \%$, respectively). The medians of NT-proBNP and estimated glomerular filtration rate (GFR) were $3,250 \mathrm{ng} / \mathrm{L}$ and $45 \mathrm{~mL} / \mathrm{min} / 1.73 \mathrm{~m}^{2}$ on admission, respectively. In the first-step treatment, more than half of all patients were treated with a bolus injection of diuretics (57\%); non-invasive positive pressure ventilation was used in $13 \%$. The most frequent prescription at discharge was a loop diuretic (79\%), which was the most increased treatment during hospitalization.

According to the quantiles of plasma osmolality on admission (293.2 and $300.3 \mathrm{mOsm} / \mathrm{kg}$ ), we divided patients into three groups. Background and general information on admission are described in the right column of Table 1. Among the components for the osmolality calculation (serum sodium, blood urea nitrogen, and glucose), serum sodium and blood urea nitrogen were significantly elevated in accordance with the elevation of plasma osmolality. In the higher osmolality groups, hypertension, diabetes mellitus, dyslipidemia and chronic kidney disease were prevalent. The higher osmolality groups showed renal dysfunction, and NT-proBNP of the highest quantile group (Q3) was significantly higher than those in other groups. Echocardiography on admission showed generally comparable between groups. In acute phase treatment, intravenous usage of carperitide was more frequent in the Q3 group. At discharge (right column of Table 2) higher osmolality groups on admission still had higher osmolality at discharge, and the medians plasma osmolality of Q2 and Q3 had decreased to just around the upper limit of normal. The higher osmolality groups also had significantly lower estimated GFR compared with lower osmolality groups.

\section{Plasma osmolality and prognosis}

Among 960 patients, 216 patients (22.5\%) suffered composite endpoint with a mean \pm standard deviation (SD) follow-up of $366 \pm 356$ days. As far as the secondary endpoint, 62 patients $(6.5 \%)$ reached cardiac mortality in $444 \pm 378$ days, 204 (21.3\%) re-admitted for HF in $366 \pm 356$ days. The Kaplan-Meier curves revealed that higher plasma osmolality was significantly associated with the primary endpoint (Log-rank $P=0.0095$ ) (Figure 2). Univariable Cox regression tests revealed that the significance was observed particularly between the highest osmolality group (Q3) versus the lowest osmolality group (Q1) (HR 1.61; 95\% Cl 1.16-2.23, $P=0.0120$ ) (Table 3). Regarding the secondary endpoint, in the Kaplan-Meier curve analyses, $\mathrm{HF}$ readmission was also significantly more frequent in the higher osmolality group (Logrank $P=0.0425$ ), which was not in case with cardiac mortality (Log-rank $P=0.0937$ ) (Figure 2$)$. Through 
univariable Cox regression tests for clinically important parameters on admission, higher age, higher NTproBNP, and higher plasma osmolality were associated with the primary endpoint (left column of Table 4). Moreover, these confounders were shown to be independently associated with the primary endpoint through multivariable Cox regression analysis (right column of Table 4).

We further examined the event risk of a composite endpoint among the quantiles stratified by plasma osmolality at discharge. The Kaplan-Meier curve showed that the event risk was not associated with the osmolality at discharge in this cohort (Log-rank $P=0.1976$, Online Figure S1).

\section{Discussion}

In this study, we showed that higher plasma osmolality on admission was an important prognostic factor for HFpEF patients. Although a few reports have also indicated that plasma osmolality had prognostic meaning for HF patients, their descriptions were so scattered that we were unable to reach a consensus on how to deal with this marker. Thus, our present finding in a prospective cohort that "higher plasma osmolality on admission" impairs prognosis in "hospitalized decompensated HFpEF" patients is notable.

\section{Prognostic difference in plasma osmolality between HFpEF and HFrEF}

Though a sub-analysis of the EVEREST trial for HFrEF patients, Vaduganathan et.al showed that normal osmolality at discharge was associated with improved outcomes.(13) Kaya et.al investigated clinical implication of plasma osmolality on admission for HFrEF patients.(14) They presented the third quartile of normo-to-hyperosmolality (mean of $293 \mathrm{m0sm} / \mathrm{kg}$ ) as having the smallest adverse outcome rates, while the lowest quartile (mean of $280 \mathrm{mOsm} / \mathrm{kg}$ ) showed the worst outcomes, followed by the highest quartile (mean of $301 \mathrm{mOsm} / \mathrm{kg}$ ). According to these studies, plasma osmolality in the normal range seemed to be quite important for HFrEF patients. This finding should also be related to the particular prognostic importance of hyponatremia in HFrEF.(22) Contrary to these reports, Arévalo-Lorido et.al reported that the frequency of adverse outcomes increased in accordance with the increase in osmolality on admission in $\operatorname{ADHF}(15)$, similarly to our findings. Although their registry did not group subjects by LVEF, about $70 \%$ of the patients had LVEFs $>45 \%$, indicating that HFrEF was underrepresented in that cohort. Taken our present findings together with those of Arévalo-Lorido et.al, we conclude that the elevation of plasma osmolality on admission raises the predictability of adverse outcomes in decompensated HFpEF patients.

\section{Cause of higher plasma osmolality in HFpEF patients}

Different from HFrEF patients, higher plasma osmolality on admission was related to adverse outcomes in HFpEF patients. It should be noted that the plasma osmolality on admission in our HFpEF cohort (median of $297 \mathrm{mOsm} / \mathrm{kg}$, Table 1) was generally higher than that of a previous reported HFrEF cohort (median of approximately $290 \mathrm{mOsm} / \mathrm{kg}$ ).(14) In an experimental study(12), excessive RAAS activation was proven to cause osmolality elevation in the acute phase of a rapid pacing HF model. RAAS activation could cause sodium reabsorption through modulation of the GFR, tubuloglomerular feedback, 
glomerulotubular balance, and distal tubular reabsorption(23), which could increase plasma osmolality. Relative hypovolemia in the higher osmolality groups compared with the lower osmolality groups was not likely to be the cause of RAAS activation because PVS was comparable between groups (Table 1). AVP is known to be an another cause of volume retention, and increased AVP activity causes a decrease in osmolality accompanied by hyponatremia in HFrEF patients.(24) In contrast, age-related attenuation of the AVP response(25) could be more common in elderly HFpEF patients than in younger HFrEF patients. Excessive RAAS activation compared to AVP activity might contribute to the higher plasma osmolality in HFpEF compared to HFrEF patients.

\section{Prognostic implication of higher plasma osmolality on admission}

We showed that higher plasma osmolality on admission was associated with poorer prognosis in HFpEF patients. The prognostic impact of the AVP system in HF has not been fully elucidated. Because of the short half-life of AVP, it is not practical to measure plasma AVP as a prognostic marker. In this point, copeptin has attracted attention owing to its creation from prepro-vasopressin at the same time as AVP and longer half-life.(26) Some reports have shown the prognostic implications of copeptin for HF.(27) (28) Although plasma osmolality on admission is not necessarily determined by the AVP system, there is a report consistent with our findings. Hage et. al described the prognostic meaning of copeptin in a prospective HFpEF cohort (KaRen-study) and clarified that copeptin was elevated in HFpEF patients and had partial prognostic implications, which were blunted after adjustment for NT-proBNP.(29) The relevance of neurohormonal balance and pathophysiology in HFpEF should be further investigated.

\section{What are the clinical implications?}

The following variables have reported as prognostic markers in the acute phase in HFpEF patients: TRPG(30), lung congestion observed as B-lines ('comets') on lung ultrasound(31), soluble suppression of tumorigenesis-2 with NT-proBNP(32) and cystatin C.(33) In addition to these factors, our findings showed that higher plasma osmolality also has important prognostic implications in the acute phase of HFpEF.

The higher osmolality groups presented even higher plasma osmolality than lower osmolality groups at discharge (Table 2), which showed those who had extremely elevated osmolality in the acute phase may suffer from some unfavorable factors which permanently raise the plasma osmolality. It is possible that those who have higher osmolality both on admission and at discharge are exposed to excessive RAAS activation, and the immediate and sustainable handling of this overactivation should be considered. Although various RAAS blockers have shown definite clinical benefits in HFrEF patients, including angiotensin converting enzyme inhibitors(34), angiotensin II receptor blockers(35), angiotensin-neprilysin inhibitors(36), and mineral corticoid-receptor antagonists(37), the benefits in HFpEF patients are controversial.(38) We propose that further investigation to determine whether these approaches are particularly favorable to HFpEF patients with higher plasma osmolality is warranted.

\section{Limitations}


Several limitations of this study should be mentioned. First, although our results showed that elevated plasma osmolality on admission was associated with poor outcomes, we could not examine whether extremely decreased plasma osmolality affected prognosis because only $42(4.4 \%)$ subjects had $<275$ $\mathrm{mOsm} / \mathrm{kg}$ on admission. Of note, this finding that excessively low plasma osmolality may be rare in acute decompensated HFpEF patients is important. Second, there have been several formulas which are able to calculate plasma osmolality, and Fazekas et al. reported a formula developed by Zander showed excellent concordance with measured osmolality.(39) Zander's formula included lactate and bicarbonate to calculate osmolality, however, we have not measured these parameters in our study. We selected the formula consisted of sodium, blood urea nitrogen and glucose, which was also used in the previous article investigated among HFrEF patients.(14) Third, the present study was a multicenter prospective Asian cohort with quite elder patients (median age of as high as 83 years), which would limit the generalizability of the current findings for other races. Fourth, despite multivariable analysis, residual confounding from unmeasured factors may have affected the results. Finally, although we speculated that RAAS activity, and not AVP activity, was responsible for the poor outcomes, we did not measure either urine osmolality or neurohormonal factors substituting for RAAS.

\section{Conclusion}

We show here higher plasma osmolality on admission was associated with poor outcomes in HFpEF patients. Further investigation to confirm the results of this small study and to support our understanding of the pathophysiological meaning of plasma osmolality in HFpEF patients is warranted.

\section{Abbreviations}

ADHF; acute decompensated HF

AVP; arginine vasopressin

BNP; brain natriuretic peptide

Cls; confidence intervals

GFR; glomerular filtration rate

GNRI; Geriatric Nutritional Risk Index

HF; heart failure

HFpEF; heart failure with preserved ejection fraction

HFrEF; heart failure with reduced ejection fraction

HRs; hazard ratios 
LVEF; left ventricular ejection fraction

NT-proBNP; N-terminal pro-B-type natriuretic peptide

PVS; plasma volume status

RAAS; renin-angiotensin-aldosterone system

SD; standard deviation

\section{Declarations}

\section{Availability of data and materials}

Not applicable.

\section{Acknowledgement}

The authors thank all the investigators, clinical research coordinators and data managers involved in the PURSUIT-HFpEF registry for their dedicated contributions. We thank Nagisa Yoshioka, Kyoko Tatsumi, Satomi Kishimoto, Noriko Murakami, and Sugako Mitsuoka for their excellent assistance with data collection. We thank Libby Cone, MD, MA, from DMC Corp. (http://www.dmed.co.jp/) for editing drafts of this manuscript.

\section{Sources of Funding}

This work is funded by Roche Diagnostics K.K. and Fujifilm Toyama Chemical Co. Ltd.

\section{Author information}

\section{Affiliations}

Division of Cardiology, Amagasaki Chuo Hospital, 1-12-1 Shioe, Amagasaki, Hyogo 661-0976, Japan Akito Nakagawa, Yoshio Yasumura, Chikako Yoshida, Takahiro Okumura, Jun Tateishi, and Junichi Yoshida

Department of Medical Informatics, Osaka University Graduate School of Medicine, 2-2 Yamadaoka, Suita 565-0871, Japan

Akito Nakagawa

Division of Cardiology, Osaka General Medical Center, 3-1-56 Mandaihigashi, Sumiyoshi-ku, Osaka 5588558, Japan

Shunsuke Tamaki and Takahisa Yamada 
Division of Cardiology, Osaka Rosai Hospital, 3-1179 Nagasonecho, Kita-ku, Sakai, Osaka 591-8025, Japan

Masamichi Yano

Cardiovascular Division, Osaka Police Hospital, 10-31 Kitayamacho, Tennojiku, Osaka 543-0035, Japan

Takaharu Hayashi

Division of Cardiology, Kawanishi City Hospital, 5-21-1, Kawanishi, Hyogo 666-0195, Japan

Yusuke Nakagawa

Department of Cardiovascular Medicine, Osaka University Graduate School of Medicine, 2-2 Yamadaoka, Suita 565-0871, Japan

Daisaku Nakatani, Shungo Hikoso, and Yasushi Sakata

\section{Contributions}

Y.S. has the responsibility on the administration of this cohort study, supervised by Y.Y. and T.Y. Patient enrollment and data correction were directed by A.N., C.Y., T.O., J.T., J.Y., S.T., M.Y., T.H., and Y.N. A.N. provided conceptualization, methodology, formal analysis, and original draft writing of the investigation. Critical draft review and editing were added by Y.Y., S.H. and Y.S. Funding acquisition was provided by D.N., S.H., and Y.S. All authors had read and approved the final version of this manuscript.

\section{Corresponding author}

Correspondence to Akito Nakagawa < a-nakagawa@cardiology.med.osaka-u.ac.jp >

\section{Ethics declarations}

\section{Ethics approval and consent to participate and publish}

This study, including the procedure for enrollment, was approved by the institutional review board of each participating facility, including the official institutional review board committee of Osaka University Hospital (approved on February 24, 2016). Written informed consent, including data publication, was received from each participating patient.

\section{Statement of conflicts of interest}

Daisaku Nakatani has received honoraria from Roche Diagnostics. Shungo Hikoso has received personal fees from Daiichi Sankyo Company, Bayer, Astellas Pharma, Pfizer Pharmaceuticals and Boehringer Ingelheim Japan, and received grants from Roche Diagnostics, FUJIFILM Toyama Chemical and Actelion Pharmaceuticals. Yasushi Sakata received personal fees from Otsuka Pharmaceutical, Ono 
Pharmaceutical, Daiichi Sankyo Company, Mitsubishi Tanabe Pharma Corporation and Actelion Pharmaceuticals, and received grants form Roche Diagnostic, FUJIFILM Toyama Chemical, Abbott Medical Japan, Otsuka Pharmaceutical, Daiichi Sankyo Company, Mitsubishi Tanabe Pharma Corporation and Biotronik. Other authors have no conflicts of interest to disclose.

\section{References}

1. Ponikowski P, Voors AA, Anker SD, Bueno H, Cleland JGF, Coats AJS, et al. 2016 ESC Guidelines for the diagnosis and treatment of acute and chronic heart failure: The Task Force for the diagnosis and treatment of acute and chronic heart failure of the European Society of Cardiology (ESC)Developed with the special contribution of the Heart Failure Association (HFA) of the ESC. European heart journal. 2016;37(27):2129-200.

2. Redfield MM. Heart Failure with Preserved Ejection Fraction. The New England journal of medicine. 2016;375(19):1868-77.

3. Borlaug BA. The pathophysiology of heart failure with preserved ejection fraction. Nature reviews Cardiology. 2014;11(9):507-15.

4. Rasouli M. Basic concepts and practical equations on osmolality: Biochemical approach. Clinical biochemistry. 2016;49(12):936-41.

5. Gheorghiade M, Abraham WT, Albert NM, Gattis Stough W, Greenberg BH, O'Connor CM, et al. Relationship between admission serum sodium concentration and clinical outcomes in patients hospitalized for heart failure: an analysis from the OPTIMIZE-HF registry. European heart journal. 2007;28(8):980-8.

6. Jujo K, Minami Y, Haruki S, Matsue Y, Shimazaki K, Kadowaki H, et al. Persistent high blood urea nitrogen level is associated with increased risk of cardiovascular events in patients with acute heart failure. ESC heart failure. 2017;4(4):545-53.

7. Mebazaa A, Gayat E, Lassus J, Meas T, Mueller C, Maggioni A, et al. Association between elevated blood glucose and outcome in acute heart failure: results from an international observational cohort. Journal of the American College of Cardiology. 2013;61(8):820-9.

8. Prenner SB, Pillutla R, Yenigalla S, Gaddam S, Lee J, Obeid MJ, et al. Serum Albumin Is a Marker of Myocardial Fibrosis, Adverse Pulsatile Aortic Hemodynamics, and Prognosis in Heart Failure With Preserved Ejection Fraction. Journal of the American Heart Association. 2020;9(3):e014716.

9. Smith GL, Lichtman JH, Bracken MB, Shlipak MG, Phillips CO, DiCapua P, et al. Renal impairment and outcomes in heart failure: systematic review and meta-analysis. Journal of the American College of Cardiology. 2006;47(10):1987-96.

10. Chatterjee K. Neurohormonal activation in congestive heart failure and the role of vasopressin. The American journal of cardiology. 2005;95(9a):8b-13b.

11. Robertson GL, Shelton RL, Athar S. The osmoregulation of vasopressin. Kidney international. 1976;10(1):25-37. 
12. Riegger AJ, Liebau G. The renin-angiotensin-aldosterone system, antidiuretic hormone and sympathetic nerve activity in an experimental model of congestive heart failure in the dog. Clinical science (London, England : 1979). 1982;62(5):465-9.

13. Vaduganathan M, Marti CN, Mentz RJ, Greene SJ, Ambrosy AP, Subacius HP, et al. Serum Osmolality and Postdischarge Outcomes After Hospitalization for Heart Failure. The American journal of cardiology. 2016;117(7):1144-50.

14. Kaya $H$, Yucel O, Ege MR, Zorlu A, Yucel H, Gunes $H$, et al. Plasma osmolality predicts mortality in patients with heart failure with reduced ejection fraction. Kardiologia polska. 2017;75(4):316-22.

15. Arevalo-Lorido JC, Gomez JC, Formiga F, Conde-Martel A, Carrera-Izquierdo M, Muela-Molinero A, et al. High serum osmolarity at admission determines a worse outcome in patients with heart failure: Is a new target emerging? International journal of cardiology. 2016;221:238-42.

16. Suna S, Hikoso S, Yamada T, Uematsu M, Yasumura Y, Nakagawa A, et al. Study protocol for the PURSUIT-HFpEF study: a Prospective, Multicenter, Observational Study of Patients with Heart Failure with Preserved Ejection Fraction. BMJ open. 2020;10(10):e038294.

17. Matsumura Y, Hattori A, Manabe S, Takahashi D, Yamamoto Y, Murata T, et al. Case Report Form Reporter: A Key Component for the Integration of Electronic Medical Records and the Electronic Data Capture System. Studies in health technology and informatics. 2017;245:516-20.

18. Kinugasa $Y$, Kato M, Sugihara S, Hirai M, Yamada K, Yanagihara K, et al. Geriatric nutritional risk index predicts functional dependency and mortality in patients with heart failure with preserved ejection fraction. Circulation journal : official journal of the Japanese Circulation Society. 2013;77(3):705-11.

19. Ling HZ, Flint J, Damgaard M, Bonfils PK, Cheng AS, Aggarwal S, et al. Calculated plasma volume status and prognosis in chronic heart failure. European journal of heart failure. 2015;17(1):35-43.

20. Lang RM, Badano LP, Mor-Avi V, Afilalo J, Armstrong A, Ernande L, et al. Recommendations for cardiac chamber quantification by echocardiography in adults: an update from the American Society of Echocardiography and the European Association of Cardiovascular Imaging. Journal of the American Society of Echocardiography : official publication of the American Society of Echocardiography. 2015;28(1):1-39.e14.

21. Fazekas AS, Funk GC, Klobassa DS, Ruther H, Ziegler I, Zander R, et al. Evaluation of 36 formulas for calculating plasma osmolality. Intensive care medicine. 2013;39(2):302-8.

22. Rusinaru D, Tribouilloy C, Berry C, Richards AM, Whalley GA, Earle N, et al. Relationship of serum sodium concentration to mortality in a wide spectrum of heart failure patients with preserved and with reduced ejection fraction: an individual patient data meta-analysis(dagger): Meta-Analysis Global Group in Chronic heart failure (MAGGIC). European journal of heart failure. 2012;14(10):113946.

23. Bie P, Damkjaer M. Renin secretion and total body sodium: pathways of integrative control. Clinical and experimental pharmacology \& physiology. 2010;37(2):e34-42. 
24. Oren RM. Hyponatremia in congestive heart failure. The American journal of cardiology. 2005;95(9a):2b-7b.

25. Rowe JW, Minaker KL, Sparrow D, Robertson GL. Age-related failure of volume-pressure-mediated vasopressin release. The Journal of clinical endocrinology and metabolism. 1982;54(3):661-4.

26. Christ-Crain M, Fenske W. Copeptin in the diagnosis of vasopressin-dependent disorders of fluid homeostasis. Nature reviews Endocrinology. 2016;12(3):168-76.

27. Schurtz G, Lamblin N, Bauters C, Goldstein P, Lemesle G. Copeptin in acute coronary syndromes and heart failure management: State of the art and future directions. Archives of cardiovascular diseases. 2015;108(6-7):398-407.

28. Zhong Y, Wang R, Yan L, Lin M, Liu X, You T. Copeptin in heart failure: Review and meta-analysis. Clinica chimica acta; international journal of clinical chemistry. 2017;475:36-43.

29. Hage C, Lund LH, Donal E, Daubert JC, Linde C, Mellbin L. Copeptin in patients with heart failure and preserved ejection fraction: a report from the prospective KaRen-study. Open heart. 2015;2(1):e000260.

30. Omote K, Nagai T, Kamiya K, Aikawa T, Tsujinaga S, Kato Y, et al. Long-term Prognostic Significance of Admission Tricuspid Regurgitation Pressure Gradient in Hospitalized Patients With Heart Failure With Preserved Ejection Fraction: A Report From the Japanese Real-World Multicenter Registry. Journal of cardiac failure. 2019;25(12):978-85.

31. Palazzuoli A, Ruocco G, Beltrami M, Nuti R, Cleland JG. Combined use of lung ultrasound, B-type natriuretic peptide, and echocardiography for outcome prediction in patients with acute HFrEF and HFpEF. Clinical research in cardiology : official journal of the German Cardiac Society. 2018;107(7):586-96.

32. Huang A, Qi X, Hou W, Qi Y, Zhao N, Liu K. Prognostic value of sST2 and NT-proBNP at admission in heart failure with preserved, mid-ranged and reduced ejection fraction. Acta cardiologica. 2018;73(1):41-8.

33. Carrasco-Sanchez FJ, Galisteo-Almeda L, Paez-Rubio I, Martinez-Marcos FJ, Camacho-Vazquez C, Ruiz-Frutos $\mathrm{C}$, et al. Prognostic value of cystatin $\mathrm{C}$ on admission in heart failure with preserved ejection fraction. Journal of cardiac failure. 2011;17(1):31-8.

34. Yusuf S, Pitt B, Davis CE, Hood WB, Cohn JN. Effect of enalapril on survival in patients with reduced left ventricular ejection fractions and congestive heart failure. The New England journal of medicine. 1991;325(5):293-302.

35. McMurray JJ, Ostergren J, Swedberg K, Granger CB, Held P, Michelson EL, et al. Effects of candesartan in patients with chronic heart failure and reduced left-ventricular systolic function taking angiotensin-converting-enzyme inhibitors: the CHARM-Added trial. Lancet (London, England). 2003;362(9386):767-71.

36. McMurray JJ, Packer M, Desai AS, Gong J, Lefkowitz MP, Rizkala AR, et al. Angiotensin-neprilysin inhibition versus enalapril in heart failure. The New England journal of medicine. 2014;371(11):9931004. 
37. Pitt B, Zannad F, Remme WJ, Cody R, Castaigne A, Perez A, et al. The effect of spironolactone on morbidity and mortality in patients with severe heart failure. Randomized Aldactone Evaluation Study Investigators. The New England journal of medicine. 1999;341(10):709-17.

38. Solomon SD, McMurray JJV, Anand IS, Ge J, Lam CSP, Maggioni AP, et al. Angiotensin-Neprilysin Inhibition in Heart Failure with Preserved Ejection Fraction. The New England journal of medicine. 2019;381(17):1609-20.

39. Fazekas AS, Funk GC, Klobassa DS, Rüther $H$, Ziegler I, Zander R, et al. Evaluation of 36 formulas for calculating plasma osmolality. Intensive care medicine. 2013;39(2):302-8.

\section{Tables}

Table 1. Baseline characteristics and data on admission divided by plasma osmolality 


\begin{tabular}{|c|c|c|c|c|c|}
\hline & $\begin{array}{l}\text { All patients } \\
(\mathrm{n}=960)\end{array}$ & $\begin{array}{l}\text { Q1 }(\mathrm{n}= \\
318) \\
\text { Osm }< \\
293.2\end{array}$ & $\begin{array}{l}\text { Q2 }(n=322) \\
293.2 \leq \\
\text { Osm }<300.3\end{array}$ & $\begin{array}{l}\text { Q3 }(n=320) \\
300.3 \leq 0 s m\end{array}$ & $\begin{array}{l}P \text { - } \\
\text { value }\end{array}$ \\
\hline Age, years & $83(77-87)$ & $83(77-87)$ & $83(77-87)$ & $83(77-87)$ & 0.9761 \\
\hline female & $524(55)$ & $178(56)$ & $179(56)$ & $167(52)$ & 0.5709 \\
\hline prior HF hospitalization & $244(26)$ & $63(20) \ddagger$ & $84(26)$ & $97(31)$ * & 0.0089 \\
\hline \multicolumn{6}{|l|}{ comorbidities } \\
\hline Hypertension & $809(85)$ & $254(80) \ddagger$ & $272(85)$ & $183(89)$ * & 0.0112 \\
\hline Diabetes & $314(33)$ & $87(28) \ddagger$ & $93(29) \ddagger$ & $134(42) *, \dagger$ & $\overleftarrow{0} .0001$ \\
\hline Dyslipidemia & $393(41)$ & $111(35) \ddagger$ & $128(40)$ & $154(48)$ * & 0.0036 \\
\hline COPD & $73(8)$ & $25(8)$ & $21(7)$ & $27(9)$ & 0.6247 \\
\hline CKD & $384(40)$ & $97(31) \ddagger$ & $118(37) \ddagger$ & $169(53) *, \dagger$ & $<0001$ \\
\hline malignancy & $112(12)$ & $36(12)$ & $33(10)$ & $43(14)$ & 0.4165 \\
\hline \multicolumn{6}{|l|}{$\begin{array}{l}\text { General condition on } \\
\text { admission }\end{array}$} \\
\hline $\mathrm{BMI}, \mathrm{kg} / \mathrm{m}^{2}$ & $\begin{array}{l}23.8 \\
(21.0- \\
26.9)\end{array}$ & $\begin{array}{l}23.2(20.6- \\
26.5) \neq\end{array}$ & $\begin{array}{l}23.7(20.9- \\
26.8)\end{array}$ & $\begin{array}{l}24.6(21.9- \\
27.7) *\end{array}$ & 0.0022 \\
\hline SBP, mmHg & $\begin{array}{l}147(128- \\
170)\end{array}$ & $\begin{array}{l}146(129- \\
166)\end{array}$ & $\begin{array}{l}149(127- \\
167)\end{array}$ & $\begin{array}{l}149(128- \\
175)\end{array}$ & 0.3444 \\
\hline $\mathrm{DBP}, \mathrm{mmHg}$ & $80(66-93)$ & $82(69-92)$ & $80(67-94)$ & $76(64-93)$ & 0.2598 \\
\hline Heart rate & $\begin{array}{l}82(67- \\
100)\end{array}$ & $\begin{array}{l}82(68- \\
102)\end{array}$ & $82(68-99)$ & $82(65-100)$ & 0.7596 \\
\hline $\mathrm{AF}$ & $444(46)$ & $153(48)$ & $154(48)$ & $137(43)$ & 0.3187 \\
\hline GNRI & $\begin{array}{l}98(90- \\
106)\end{array}$ & $\begin{array}{l}96(89- \\
103) \ddagger\end{array}$ & $98(90-106)$ & $\begin{array}{l}100(92-107) \\
\star\end{array}$ & 0.0110 \\
\hline \multicolumn{6}{|l|}{$\begin{array}{l}\text { Laboratory examination } \\
\text { on admission }\end{array}$} \\
\hline Hemoglobin, g/dL & $\begin{array}{l}11.1(9.8- \\
12.5)\end{array}$ & $\begin{array}{l}11.5(10.1- \\
12.7) \neq\end{array}$ & $\begin{array}{l}11.4(10.1- \\
12.7) \ddagger\end{array}$ & $\begin{array}{l}10.7(9.4- \\
12.3) \star,+\end{array}$ & $\begin{array}{l}< \\
0.0001\end{array}$ \\
\hline Hematocrit, \% & $34(30-38)$ & $\begin{array}{l}35(31-38) \\
\ddagger\end{array}$ & $\begin{array}{l}35(31-38) \\
\neq\end{array}$ & $\begin{array}{l}33(29-38) \\
*,+\end{array}$ & 0.0033 \\
\hline Serum total protein, $\mathrm{g} / \mathrm{dL}$ & $6.7(6.3-$ & $6.7(6.3-$ & $6.7(6.3-$ & $6.7(6.2-7.1)$ & 0.3454 \\
\hline
\end{tabular}




\begin{tabular}{|c|c|c|c|c|c|}
\hline & 7.1) & 7.2) & 7.2) & & \\
\hline Serum albumin, g/dL & $\begin{array}{l}3.5(3.2- \\
3.8)\end{array}$ & $\begin{array}{l}3.5(3.1- \\
3.8)\end{array}$ & $\begin{array}{l}3.5(3.2- \\
3.9)\end{array}$ & $3.5(3.1-3.8)$ & 0.3340 \\
\hline $\mathrm{BUN}, \mathrm{mg} / \mathrm{dL}$ & $22(16-32)$ & $\begin{array}{l}18(14-24) \\
+, \ddagger\end{array}$ & $21(15-27)$ & $\begin{array}{l}31(23-43) \\
*,+\end{array}$ & $<0.0001$ \\
\hline Creatinine, mg/dL & $\begin{array}{l}1.1(0.8- \\
1.5)\end{array}$ & $\begin{array}{l}1.0(0.7- \\
1.2)+, \ddagger\end{array}$ & $\begin{array}{l}1.0(0.8- \\
1.3)^{*}, \neq\end{array}$ & $\begin{array}{l}1.4(0.9-2.0) \\
*,+\end{array}$ & $<.0001$ \\
\hline eGFR, $\mathrm{mL} / \mathrm{min} / 1.73 \mathrm{~m}^{2}$ & $45(30-58)$ & $\begin{array}{l}51(38-65) \\
t, \neq\end{array}$ & $\begin{array}{l}45(33-59) \\
\star, \neq\end{array}$ & $\begin{array}{l}33(21-50) \\
*,+\end{array}$ & $<.0001$ \\
\hline Serum sodium, mEq/L & $\begin{array}{l}140(137- \\
142)\end{array}$ & $\begin{array}{l}137(134- \\
138)+, \neq\end{array}$ & $\begin{array}{l}141(139- \\
142) * * \neq\end{array}$ & $\begin{array}{l}142(140- \\
144) *+\dagger\end{array}$ & $\stackrel{<}{0.0001}$ \\
\hline Serum potassium, $\mathrm{mEq} / \mathrm{L}$ & $\begin{array}{l}4.1(3.7- \\
4.5)\end{array}$ & $\begin{array}{l}4.2(3.8- \\
4.5)+\end{array}$ & $\begin{array}{l}4.0(3.7- \\
4.4) \star, \neq\end{array}$ & $\begin{array}{l}4.2(3.7-4.6) \\
t\end{array}$ & 0.0084 \\
\hline Serum chloride, $\mathrm{mEq} / \mathrm{L}$ & $\begin{array}{l}105(101- \\
108)\end{array}$ & $\begin{array}{l}101(98- \\
105)+, \ddagger\end{array}$ & $\begin{array}{l}105(103- \\
108) *, \neq\end{array}$ & $\begin{array}{l}107(104- \\
110) *+,+\end{array}$ & $<.0001$ \\
\hline NT-proBNP, ng/L & $\begin{array}{l}3250 \\
(1718- \\
6430)\end{array}$ & $\begin{array}{l}2950 \\
(1637- \\
5281) \ddagger\end{array}$ & $\begin{array}{l}2820 \\
(1580- \\
5292) \neq\end{array}$ & $\begin{array}{l}4805(2108- \\
10010) *,+\end{array}$ & $<.0001$ \\
\hline CRP, mg/dL & $\begin{array}{l}0.53 \\
(0.19- \\
1.94)\end{array}$ & $\begin{array}{l}0.64(0.21- \\
2.43)\end{array}$ & $\begin{array}{l}0.46(0.18- \\
1.47)\end{array}$ & $\begin{array}{l}0.53(0.20- \\
2.00)\end{array}$ & 0.0734 \\
\hline Glucose, mg/dL & $\begin{array}{l}122(103- \\
161)\end{array}$ & $\begin{array}{l}118(101- \\
146) \neq\end{array}$ & $\begin{array}{l}117(102- \\
147) \neq\end{array}$ & $\begin{array}{l}133(112- \\
194)^{*}+\dagger\end{array}$ & $<.0001$ \\
\hline PVS, \% & $\begin{array}{l}8.7(-0.4- \\
16.8)\end{array}$ & $\begin{array}{l}8.3(-0.04- \\
17.4)\end{array}$ & $\begin{array}{l}7.4(-1.1- \\
15.6)\end{array}$ & $9.8(0.6-17.9)$ & 0.3156 \\
\hline $\begin{array}{l}\text { Plasma osmolality, } \\
\mathrm{mOsm} / \mathrm{kg}\end{array}$ & $\begin{array}{l}297(291- \\
303)\end{array}$ & $\begin{array}{l}288(283- \\
291)+, \neq\end{array}$ & $\begin{array}{l}297(295- \\
299) *, \neq\end{array}$ & $\begin{array}{l}305(303- \\
309) *,+\end{array}$ & $<.0001$ \\
\hline \multicolumn{6}{|l|}{$\begin{array}{l}\text { Echocardiographic } \\
\text { variables on admission }\end{array}$} \\
\hline LVDd, mm & $46(42-51)$ & $\begin{array}{l}46(41-49) \\
\ddagger\end{array}$ & $46(41-51)$ & $47(43-51)$ * & 0.0066 \\
\hline LVEF, \% & $60(56-65)$ & $60(56-67)$ & $61(56-65)$ & $60(55-65)$ & 0.8524 \\
\hline LAD, mm & $44(40-50)$ & $44(39-49)$ & $45(40-51)$ & $45(39-50)$ & 0.1973 \\
\hline $\mathrm{E} / \mathrm{A}$ & $\begin{array}{l}1.0(0.7- \\
1.5)\end{array}$ & $\begin{array}{l}1.1(0.7- \\
1.5)\end{array}$ & $\begin{array}{l}1.1(0.7- \\
1.7)\end{array}$ & $0.9(0.7-1.5)$ & 0.4369 \\
\hline$E / e^{\prime}$ & $16(12-21)$ & $\begin{array}{l}16(12-20) \\
\ddagger\end{array}$ & $16(12-21)$ & $17(13-22)$ * & 0.0311 \\
\hline TRPG, mmHg & $36(28-45)$ & $36(28-45)$ & $36(29-45)$ & $36(29-45)$ & 0.9959 \\
\hline IVC max, mm & $19(15-22)$ & $18(15-22)$ & $18(15-22)$ & $19(16-22)+$ & 0.0548 \\
\hline
\end{tabular}




$\begin{array}{llllll}\text { IVC collapsibility } & 0.44 & 0.38(0.23- & 0.48(0.30- & 0.44(0.29- & 0.0009 \\ & (0.28- & 0.55) \dagger & 0.59)^{*} & 0.56) & \\ & 0.57) & & & \end{array}$

Acute phase treatment

NIPPV usage

121 (13)

$36(11) \ddagger$

$26(8) \ddagger$

$59(19) *,+$

0.0003

intubation

$16(1.7)$

$3(0.9)$

$2(0.6) \neq$

$11(3) \dagger$

0.0094

DOA (continuous

$1(0.1)$

$0(0)$

$0(0)$

$1(0.3)$

0.3663

injection)

DOB (continuous

injection)

NAD (continuous

injection)

PDE3I (continuous

injection)

$17(1.7) \quad 2(0.6)$

7 (2)

8 (3)

0.1591

carperitide (continuous

injection)

$10(1.0)$

$3(0.9)$

$3(0.9)$

$4(1.3)$

0.9018

nitrates (continuous

injection)

$3(0.3)$

$0(0)$

$2(0.6)$

$1(0.3)$

0.3717

Ca channel blocker

(continuous injection)

207 (22)

$54(17) \ddagger$

$66(21)$

$87(27)$ *

0.0063

Nicorandil (continuous

injection)

$264(28)$

$85(27)$

$80(25)$

99 (31)

0.1989

diuretics (continuous

injection)

77 (8)

$18(6) \ddagger$

$23(7)$

$36(11)$ *

0.0255

diuretics (bolus injectio
Prescription before
admission

\begin{tabular}{llllll} 
Antiplatelet & $292(30)$ & $91(29)$ & $95(30)$ & $106(33)$ & 0.4225 \\
\hline ACE inhibitor or ARB & $481(50)$ & $149(47)$ & $156(48)$ & $176(55)$ & 0.0924 \\
calcium channel blocker & $489(51)$ & $148(47)$ & $162(50)$ & $179(56)$ & 0.0575 \\
\hline$\beta$-blocker & $444(46)$ & $136(43)$ & $155(48)$ & $153(48)$ & 0.3031 \\
\hline loop diuretics & $483(50)$ & $133(42) \neq$ & $165(51)$ & $185(58) *$ & 0.0003 \\
thiazide & $72(8)$ & $33(10)+$ & $13(4) *$ & $26(8)$ & 0.0085 \\
tolvaptan & $52(5)$ & $14(4)$ & $22(7)$ & $16(5)$ & 0.3667 \\
aldosterone antagonist & $204(21)$ & $\begin{array}{c}72(23) \\
\text { Page } 18 / 25\end{array}$ & $68(21)$ & $64(20)$ & 0.7153
\end{tabular}




\begin{tabular}{|llllll|}
\hline SGLT2 inhibitor & $15(1.6)$ & $6(1.9)$ & $2(0.6)$ & $7(2)$ & 0.2363 \\
\hline anticoagulant & $424(44)$ & $154(48)$ & $145(45)$ & $125(39)$ & 0.0545 \\
\hline
\end{tabular}

Values are given as median (IQR) or $\mathrm{n}(\%)$.

Abbreviations: $A C E$, angiotensin-converting enzyme; $A F$, atrial fibrillation; $A R B$, angiotensin receptor blocker; BMI, body mass index; BUN, blood urea nitrogen; Ca channel, calcium channel; CKD, chronic kidney disease; COPD, chronic obstructive pulmonary disease; CRP,C-reactive protein; DBP, diastolic blood pressure; DOA, dopamine; DOB, dobutamine; eGFR, estimated glomerular filtration rate; GNRI, Geriatric Nutritional Risk Index; HF, heart failure; IVC, inferior vena cava; LAD, left atrial dimension; LVDd, left ventricular end-diastolic diameter; LVEF, left ventricular ejection fraction; NAD, noradrenaline; NIPPV, noninvasive positive pressure ventilation; NT-proBNP, N-terminal pro-B-type natriuretic peptide; Osm, plasma osmolality (mOsm/kg); PCl, percutaneous catheter intervention; PDE3I,phosphodiesterase-3 inhibitor; PVS, plasma volume status; SBP, systolic blood pressure; SGLT2, sodium glucose cotransporter 2; TRPG, tricuspid regurgitation pressure gradient

Statistical comparisons were performed using Kruskal Wallis test or Fisher's exact test. Statistical significances between each group $(P<0.05)$ using Steel-Dwass test for continuous variables and Fisher's exact test with Bonferroni adjustment for categorical variables are shown as following: significance in versus Q1*, versus Q2†, and versus Q3ł.

Table 2. Clinical and study characteristics at discharge divided by plasma osmolality on admission 


\begin{tabular}{|c|c|c|c|c|c|}
\hline \multirow{2}{*}{$\begin{array}{l}\text { general condition at } \\
\text { discharge }\end{array}$} & All patients & Q1 ( $\mathrm{n}=318)$ & Q2 (n = 322) & Q3 (n = 320) & \multirow{2}{*}{$\begin{array}{l}P \text { - } \\
\text { value }\end{array}$} \\
\hline & $(n=960)$ & $\begin{array}{l}\text { Osm < } \\
293.2\end{array}$ & $\begin{array}{l}293.2 \leq 0 \mathrm{sm} \\
<300.3\end{array}$ & $300.3 \leq$ Osm & \\
\hline $\mathrm{BMI}, \mathrm{kg} / \mathrm{m}^{2}$ & $\begin{array}{l}21.4(18.9- \\
24.2)\end{array}$ & $\begin{array}{l}21.1(18.4- \\
23.8) \neq\end{array}$ & $\begin{array}{l}21.2(18.7- \\
24.3)\end{array}$ & $\begin{array}{l}21.9(19.4- \\
24.6) *\end{array}$ & 0.0150 \\
\hline SBP, mmHg & $\begin{array}{l}118(106- \\
131)\end{array}$ & $\begin{array}{l}117(106- \\
128) \neq\end{array}$ & $\begin{array}{l}118(106- \\
130)\end{array}$ & $\begin{array}{l}122(107- \\
134) *\end{array}$ & 0.0106 \\
\hline $\mathrm{DBP}, \mathrm{mmHg}$ & $65(58-73)$ & $65(58-73)$ & $66(58-74)$ & $65(57-73)$ & 0.7041 \\
\hline Heart rate & $70(61-80)$ & $70(63-80)$ & $70(61-80)$ & $70(60-78)$ & 0.5914 \\
\hline $\mathrm{AF}$ & $365(38)$ & 124 (39) & $131(41)$ & $110(34)$ & 0.2242 \\
\hline GNRI & $92(85-99)$ & $91(84-97)$ & $94(85-101)$ & $92(85-99)$ & 0.1277 \\
\hline 6MWD, m & $\begin{array}{l}260(155- \\
340)\end{array}$ & $\begin{array}{l}240(150- \\
333)\end{array}$ & $\begin{array}{l}270(156- \\
352)\end{array}$ & $\begin{array}{l}260(160- \\
338)\end{array}$ & 0.5728 \\
\hline NYHA classification & & & & & 0.6460 \\
\hline NYHA I & $340(36)$ & $111(36)$ & $106(33)$ & $123(39)$ & \\
\hline NYHA II & $538(57)$ & $173(55)$ & $193(60)$ & $172(54)$ & \\
\hline NYHA III & $67(7)$ & $26(8)$ & $20(6)$ & $21(7)$ & \\
\hline NYHA IV & $4(0.4)$ & $2(0.6)$ & $1(0.3)$ & $1(0.3)$ & \\
\hline \multicolumn{6}{|l|}{$\begin{array}{l}\text { laboratory examination } \\
\text { at discharge }\end{array}$} \\
\hline Hemoglobin, g/dL & $\begin{array}{l}11.3(10.1- \\
12.7)\end{array}$ & $\begin{array}{l}11.5(10.3- \\
12.7) \neq\end{array}$ & $\begin{array}{l}11.6(10.4- \\
13.1) \neq\end{array}$ & $\begin{array}{l}10.8(9.5- \\
12.2) *,+\end{array}$ & $\begin{array}{l}< \\
0.0001\end{array}$ \\
\hline Hematocrit, \% & $34(31-39)$ & $\begin{array}{l}35(32-38) \\
\ddagger\end{array}$ & $35(32-39) \ddagger$ & $\begin{array}{l}33(30-37) \\
*,+\end{array}$ & $<0001$ \\
\hline $\begin{array}{l}\text { Serum total protein, } \\
\mathrm{g} / \mathrm{dL}\end{array}$ & $\begin{array}{l}6.6(6.2- \\
7.1)\end{array}$ & $\begin{array}{l}6.8(6.3- \\
7.2) \neq\end{array}$ & $\begin{array}{l}6.8(6.3-7.2) \\
\neq\end{array}$ & $\begin{array}{l}6.5(6.1-7.0) \\
\star,+\end{array}$ & 0.0009 \\
\hline Serum albumin, $\mathrm{g} / \mathrm{dL}$ & $\begin{array}{l}3.4(3.1- \\
3.7)\end{array}$ & $\begin{array}{l}3.4(3.1- \\
3.7)\end{array}$ & $\begin{array}{l}3.4(3.2-3.8) \\
\ddagger\end{array}$ & $\begin{array}{l}3.3(3.1-3.6) \\
+\end{array}$ & 0.0104 \\
\hline $\mathrm{BUN}, \mathrm{mg} / \mathrm{dL}$ & $25(18-34)$ & $\begin{array}{l}22(16-28) \\
t, \ddagger\end{array}$ & $\begin{array}{l}25(18-33) \\
*, \neq\end{array}$ & $\begin{array}{l}29(21-42) \\
*,+\end{array}$ & $<.0001$ \\
\hline Creatinine, $\mu \mathrm{mol} / \mathrm{L}$ & $\begin{array}{l}1.1(0.9- \\
1.5)\end{array}$ & $\begin{array}{l}1.0(0.8- \\
1.2)+, \neq\end{array}$ & $\begin{array}{l}1.1(0.9-1.5) \\
*, \neq\end{array}$ & $\begin{array}{l}1.3(1.0-2.1) \\
\star,+\end{array}$ & $<0001$ \\
\hline eGFR, $\mathrm{mL} / \mathrm{min} / 1.73 \mathrm{~m}^{2}$ & $42(30-55)$ & $\begin{array}{l}50(37-60) \\
+, \ddagger\end{array}$ & $\begin{array}{l}42(32-54) \\
*, \neq\end{array}$ & $\begin{array}{l}33(21-49) \\
*,+\end{array}$ & $<0001$ \\
\hline Serum sodium, mEq/L & $\begin{array}{l}139(137- \\
141)\end{array}$ & $\begin{array}{l}138(135- \\
140)+, \neq\end{array}$ & $\begin{array}{l}140(138- \\
141) *, \neq\end{array}$ & $\begin{array}{l}140(138- \\
142) *\end{array}$ & $<0001$ \\
\hline
\end{tabular}




\begin{tabular}{|c|c|c|c|c|c|}
\hline $\begin{array}{l}\text { Serum potassium, } \\
\mathrm{mEq} / \mathrm{L}\end{array}$ & $\begin{array}{l}4.3(3.9- \\
4.6)\end{array}$ & $\begin{array}{l}4.3(3.9- \\
4.6)\end{array}$ & $4.3(4.0-4.6)$ & $4.3(3.9-4.6)$ & 0.8271 \\
\hline Serum chloride, $\mathrm{mEq} / \mathrm{L}$ & $\begin{array}{l}103(100- \\
106)\end{array}$ & $\begin{array}{l}102(99- \\
105) \dagger, \ddagger\end{array}$ & $\begin{array}{l}103(100- \\
105) * \star \neq\end{array}$ & $\begin{array}{l}104(101- \\
107) * *+\end{array}$ & $<.0001$ \\
\hline NT-proBNP, ng/L & $\begin{array}{l}1112(478- \\
2550)\end{array}$ & $\begin{array}{l}993(497- \\
2190) \neq\end{array}$ & $\begin{array}{l}952(439- \\
2025) \neq\end{array}$ & $\begin{array}{l}1437(510- \\
3770) \star,+\end{array}$ & 0.0010 \\
\hline $\mathrm{CRP}, \mathrm{mg} / \mathrm{dL}$ & $\begin{array}{l}0.29(0.11- \\
0.90)\end{array}$ & $\begin{array}{l}0.34(0.11- \\
1.01)\end{array}$ & $\begin{array}{l}0.28(0.11- \\
0.77)\end{array}$ & $\begin{array}{l}0.26(0.11- \\
0.93)\end{array}$ & 0.4804 \\
\hline Glucose, mg/dL & $\begin{array}{l}98(88- \\
117)\end{array}$ & $\begin{array}{l}97(87- \\
114)\end{array}$ & $98(88-117)$ & $101(89-120)$ & 0.3746 \\
\hline PVS, \% & $\begin{array}{l}11.5(1.9- \\
19.6)\end{array}$ & $\begin{array}{l}9.9(1.9- \\
20.0)\end{array}$ & $\begin{array}{l}9.6(0.9-17.9) \\
\ddagger\end{array}$ & $\begin{array}{l}13.4(3.1- \\
21.2)+\end{array}$ & 0.0411 \\
\hline $\begin{array}{l}\text { Plasma osmolality, } \\
\mathrm{mOsm} / \mathrm{kg}\end{array}$ & $\begin{array}{l}294(289- \\
299)\end{array}$ & $\begin{array}{l}290(286- \\
295)+, \neq\end{array}$ & $\begin{array}{l}294(290- \\
299) * \star \neq\end{array}$ & $\begin{array}{l}297(293- \\
302) * \star+\end{array}$ & $<.0001$ \\
\hline \multicolumn{6}{|l|}{ Prescription at discharge } \\
\hline Antiplatelet & $278(29)$ & $82(26)$ & $93(29)$ & $103(32)$ & 0.1946 \\
\hline ACE inhibitor or ARB & $510(53)$ & $157(49)$ & $168(52)$ & $185(58)$ & 0.0935 \\
\hline calcium channel blocker & $458(48)$ & $135(42) \ddagger$ & $149(46)$ & $174(55)$ * & 0.0076 \\
\hline$\beta$-blocker & $526(55)$ & $167(53)$ & $181(56)$ & $178(56)$ & 0.5896 \\
\hline loop diuretics & $754(79)$ & $243(76)$ & $254(79)$ & $257(80)$ & 0.4793 \\
\hline thiazide & $62(6)$ & $18(6)$ & $16(5)$ & $28(9)$ & 0.1165 \\
\hline tolvaptan & $156(16)$ & $39(12) \ddagger$ & $54(17)$ & $63(20)$ * & 0.0377 \\
\hline aldosterone antagonist & $383(40)$ & $125(39)$ & $141(44)$ & $117(37)$ & 0.1683 \\
\hline SGLT2 inhibitor & $50(5)$ & $13(4)$ & $12(4)$ & $25(8)$ & 0.0356 \\
\hline anticoagulant & $571(59)$ & $206(65) \ddagger$ & $198(61)$ & $167(52)$ * & 0.0035 \\
\hline
\end{tabular}

Values are given as median (IQR) or $\mathrm{n}(\%)$.

Abbreviations: 6MWD, 6-minute walk distance; $\mathrm{ACE}$, angiotensin-converting enzyme; $\mathrm{AF}$, atrial fibrillation; $A R B$, angiotensin receptor blocker; BMI, body mass index; BUN, blood urea nitrogen; CRP, C-reactive protein; DBP, diastolic blood pressure; eGFR, estimated glomerular filtration rate; GNRI, Geriatric Nutritional Risk Index; NT-proBNP, N-terminal pro-B-type natriuretic peptide; NYHA, New York heart failure functional class; Osm, plasma osmolality (mOsm/kg); PVS, plasma volume status; SBP, systolic blood pressure; SGLT2, sodium glucose cotransporter 2

Statistical comparisons were performed using Kruskal Wallis test or Fisher's exact test. Statistical significances between each group $(P<0.05)$ using Steel-Dwass test for continuous variables and Fisher's 
exact test with Bonferroni adjustment for categorical variables are shown as following: significance in versus Q1*, versus Q2†, and versus Q3¥.

Table 3. Cox regression models for prognostic prediction, divided with the internal quantile ranges of plasma osmolality on admission

\begin{tabular}{|c|c|c|}
\hline & Unadjusted HR (95\% Cl) & $P$-value \\
\hline \multicolumn{3}{|c|}{ Composite endpoint } \\
\hline Q2 versus Q1 & $1.13(0.80-1.60)$ & 1.0000 \\
\hline Q3 versus Q1 & $1.61(1.16-2.23)$ & 0.0120 \\
\hline Q3 versus Q2 & $1.42(1.03-1.96)$ & 0.0954 \\
\hline \multicolumn{3}{|c|}{ Cardiac mortality } \\
\hline Q2 versus Q1 & $0.85(0.42-1.66)$ & 1.0000 \\
\hline Q3 versus Q1 & $1.59(0.89-2.88)$ & 0.3531 \\
\hline Q3 versus Q2 & $1.88(1.01-3.61)$ & 0.1338 \\
\hline \multicolumn{3}{|c|}{ HF re-admission } \\
\hline Q2 versus Q1 & $1.12(0.79-1.60)$ & 1.0000 \\
\hline Q3 versus Q1 & $1.50(1.08-2.11)$ & 0.0504 \\
\hline Q3 versus Q2 & $1.34(1.08-2.11)$ & 0.2454 \\
\hline
\end{tabular}

Cox proportional hazard models for composite endpoint, cardiac mortality and heart failure re-admission. Composite endpoint was defined as cardiac mortality or heart failure re-admission. P-value was corrected with Bonferroni adjustment.

Abbreviations: HF, heart failure; HR, hazard ratio; Q1, plasma osmolality on admission < $293.2 \mathrm{mOsm} / \mathrm{kg}$; Q2, plasma osmolality on admission $\geq 293.2$ and $<300.3 \mathrm{mOsm} / \mathrm{kg}$; and Q3, plasma osmolality on admission $\geq 300.3 \mathrm{mOsm} / \mathrm{kg}$

Table 4. Cox regression models for prognostic prediction of the primary endpoint 


\begin{tabular}{|lllll|}
\hline & $\begin{array}{l}\text { Unadjusted HR } \\
(95 \% \mathrm{Cl})\end{array}$ & $\begin{array}{l}\text { P-value } \\
\text { Age }\end{array}$ & $\begin{array}{l}\text { Adjusted HR } \\
(95 \% \mathrm{Cl})\end{array}$ & $P$-value \\
\hline Female & $\begin{array}{l}\text { 1.86 (1.88-19.32) } \\
\text { AF }\end{array}$ & 0.0019 & $5.94(1.69-22.44)$ & 0.0050 \\
\hline HT & $0.96(0.74-1.26)$ & 0.7902 & $1.05(0.77-1.43)$ & 0.7605 \\
\hline Diabetes & $0.94(0.77-1.15)$ & 0.5207 & $0.89(0.57-1.43)$ & 0.6064 \\
\hline GNRI & $0.94(0.80-1.10)$ & 0.4475 & $1.20(0.86-1.64)$ & 0.2787 \\
\hline Log NT-proBNP & $15.04(1.93-60.70)$ & 0.0139 & $3.53(1.05-2.22)$ & 0.0283 \\
\hline Plasma Osmolality & $7.29(2.25-23.92)$ & 0.0009 & $4.70(1.33-17.35)$ & 0.0160 \\
\hline BUN & $6.87(3.36-13.52)$ & $<0.0001$ & & 0.6668 \\
\hline Serum sodium & $1.18(0.39-3.81)$ & 0.7755 & & \\
\hline Glucose & $1.58(0.46-4.66)$ & 0.4447 & & \\
\hline
\end{tabular}

Composite endpoint was defined as cardiac mortality or heart failure re-admission.

Abbreviations: AF, atrial fibrillation; BUN, blood urea nitrogen; GNRI, Geriatric Nutritional Risk Index, $\mathrm{HT}$, Hypertension; HR, hazard ratio; NT-proBNP, N-terminal pro-B-type natriuretic peptide

\section{Figures}


A. Plasma Osmolality on admission

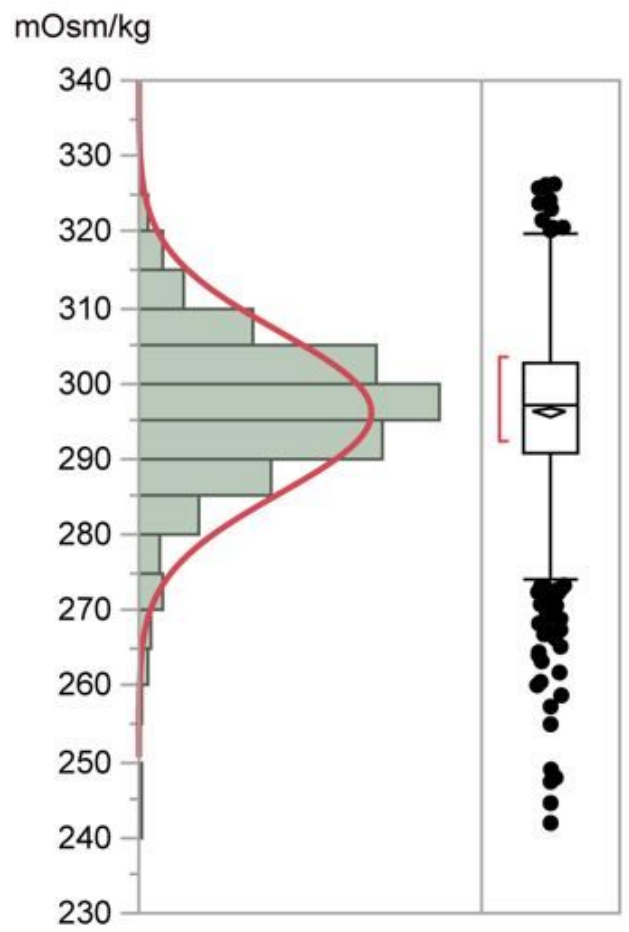

B. Plasma Osmolality at discharge

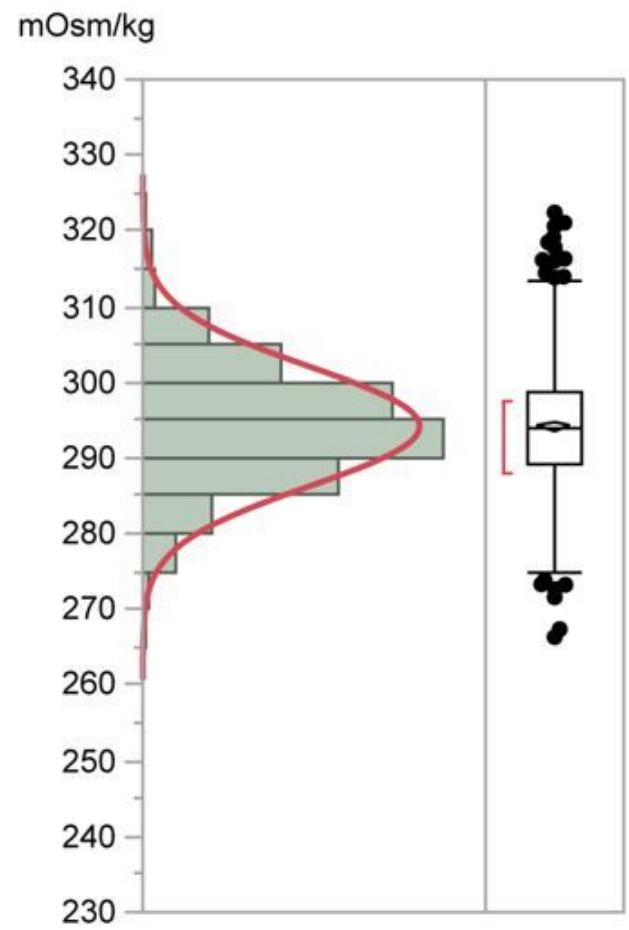

\section{Figure 1}

The distributions of plasma osmolality. Distributions of plasma osmolality on admission (A) and at discharge (B). F-test revealed that the distributions were significantly different between on admission and at discharge $(P<0.0001)$. 


\section{A. Composite endpoint}
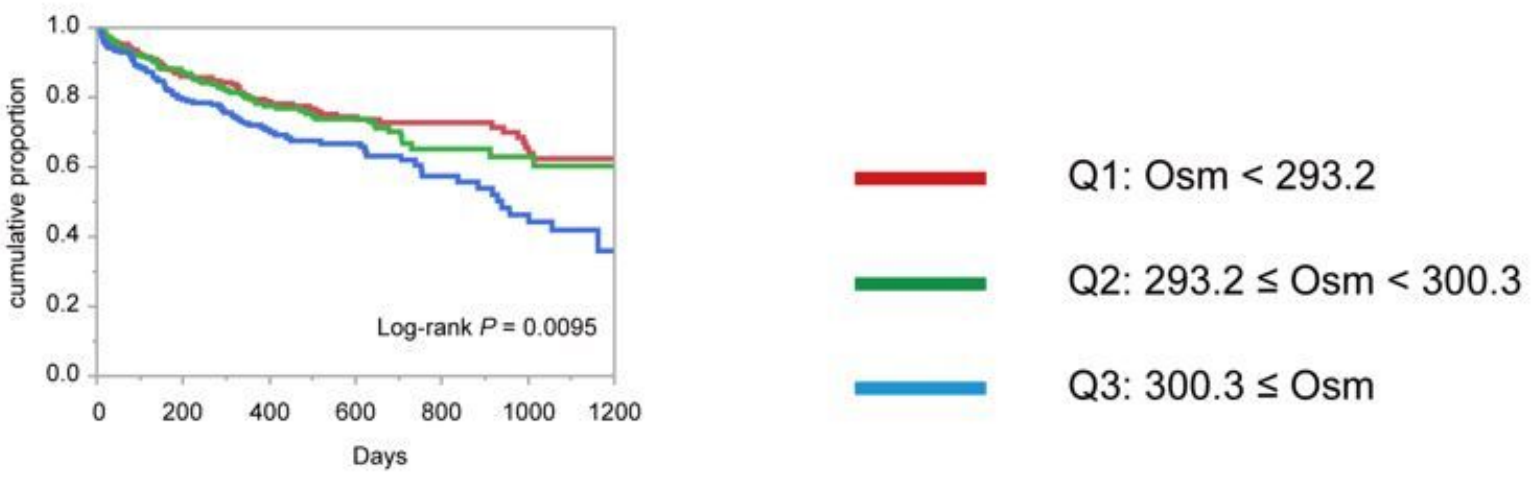

Number at risk

$\begin{array}{lllll}\text { Q1 } & 318 & 123 & 61 & 5 \\ \text { Q2 } & 322 & 114 & 33 & 3 \\ \text { Q3 } & 320 & 98 & 37 & 7\end{array}$

B. Cardiac mortality

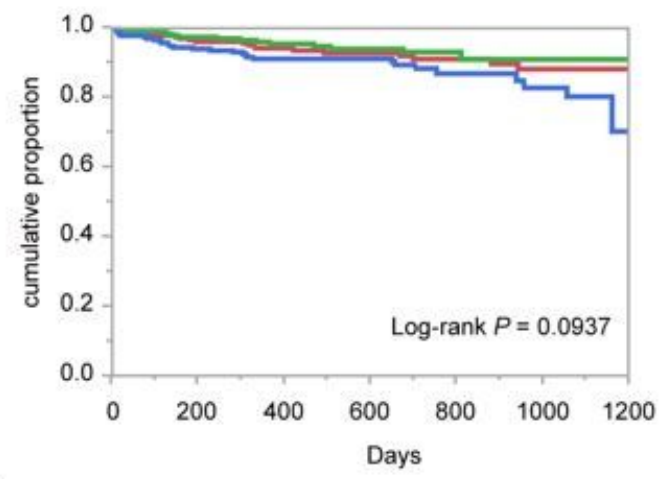

Number at risk

$\begin{array}{lllll}\text { Q1 } & 318 & 147 & 76 & 7 \\ \text { Q2 } & 322 & 146 & 49 & 3 \\ \text { Q3 } & 320 & 133 & 55 & 8\end{array}$

C. HF re-admission

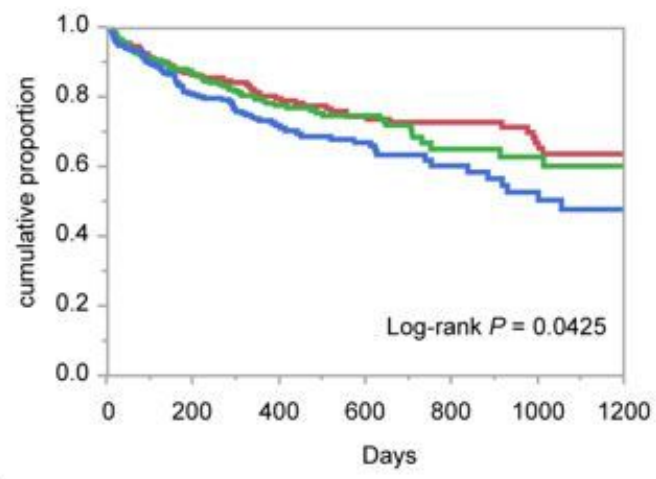

Number at risk

$\begin{array}{lllll}\text { Q1 } & 318 & 123 & 61 & 5 \\ \text { Q2 } & 322 & 114 & 33 & 3 \\ \text { Q3 } & 320 & 98 & 37 & 7\end{array}$

Figure 2

Kaplan-Meier survival curves stratified with quantiles of plasma osmolality on admission Composite endpoint was defined as cardiac mortality or heart failure re-admission. Kaplan-Meier survival curves for composite endpoint (A), cardiac mortality (B) and heart failure re-admission (C) Abbreviations: HF, heart failure; Osm, plasma osmolality $(\mathrm{mOsm} / \mathrm{kg})$ on admission 